\title{
EP2-PKA signaling is suppressed by triptolide in lipopolysaccharide-induced microglia activation
}

\author{
Ting Zhang ${ }^{1}$, Xiaoli Gong ${ }^{2}$, Guanzheng $\mathrm{Hu}^{1}$ and Xiaomin Wang ${ }^{1 *}$
}

\begin{abstract}
Background: Microglia are key players for the inflammatory responses in the central nervous system. Suppression of microglial activation and the resulting production of proinflammatory molecules are considered a promising strategy to alleviate the progression of neurodegenerative disorders. Triptolide was demonstrated as a potent anti-inflammatory compound both in vitro and in vivo. The present study explored potential signal pathways of triptolide in the lipopolysaccharide (LPS)-induced inflammatory response using primary rat microglial cells.
\end{abstract}

Findings: Microglial cells were pretreated with triptolide and stimulated with LPS. To investigate the anti-inflammatory effect of triptolide, we used Griess reagent and Western blot for NO release and iNOS expression, respectively. Moreover, we applied microglia-conditioned medium to neuronal cells and used the MTS assay to test cell viability. We found that triptolide inhibited LPS-induced NO and iNOS synthesis in microglial cells, which in turn protected neurons. To evaluate the involvement of the EP2 pathway, we used real-time PCR and Western blot to determine EP2 expression. We found that LPS induced a large increase in EP2 expression in microglia, and triptolide almost completely inhibited LPS-induced EP2 expression. Using the selective EP2 agonist butaprost and the EP2 antagonist AH6809, we determined that triptolide inhibited LPS-stimulated NO production in microglia mainly through the EP2 pathway. Additionally, by further treating triptolide-treated microglia with the downstream PKA-specific activator 6-Bnz-cAMP or the Epac-specific activator 8-pCPT-2-O-Me-cAMP, we found that 6-Bnz-cAMP but not 8-pCPT-2-O-Me-cAMP increased NO production in triptolide-LPS treated microglia. These results indicate that the EP2-PKA pathway is very important for triptolide's effects.

Conclusions: Triptolide inhibits LPS-stimulated NO production in microglia via a signaling mechanism involving EP2 and PKA. This finding may help establish the pharmacological function of triptolide in neurodegenerative disorders. Moreover, the observation of inflammatory EP2 signaling in primary microglia provides important evidence that EP2 regulates innate immunity in the central nervous system.

Keywords: Triptolide, EP2, Microglia, Neuroinflammation, Nitric oxide

\section{Findings}

Microglia, the immune-like cells of the brain, play an important role in inflammatory responses in the central nervous system (CNS) [1]. The modulation of microglial activation and their production of pro-inflammatory mediators and cytokines could also be a promising strategy to alleviate the progression of neurodegenerative disorders [2-5]. The cyclooxygenase-2 (COX-2) pathway mediates the main inflammatory responses in microglia and

\footnotetext{
* Correspondence: xmwang@ccmu.edu.cn

'Department of Neurobiology, Capital Medical University, Beijing Institute for Brain Disorders and Key Laboratory for Neurodegenerative Disorder, Ministry of Education, No. 10 Xitoutiao, Youanmenwai, Fengtai District, Beijing 100069, China

Full list of author information is available at the end of the article
}

is thus a very attractive target for researchers and drug developers [6,7]. However, the deleterious cardiovascular and cerebrovascular side effect of sustained COX-2 inhibition has led to the investigation of its downstream targets [8]. Among these targets, prostaglandin $\mathrm{E}_{2}\left(\mathrm{PGE}_{2}\right)$ signaling via its EP2 receptor subtype appears to be a major mediator of inflammatory and anaphylactic reactions within both the periphery and brain [9]. EP2 upregulation by lipopolysaccharide (LPS) contributes to cerebral oxidative damage and secondary neurotoxicity, effects that are usually accompanied by the induction of NO synthase (NOS) and cyclooxygenase (COX) activities [10]. EP2 receptor not only serves as a downstream target of COX2 but also acts to influence COX2 and iNOS expression. It was reported that iNOS and COX2 induction was completely 
absent in EP2 KO microglia after LPS treatment, indicating that EP2 was necessary for the induction of iNOS and COX2 after LPS stimulation [10]. Moreover, LPS-activated microglia-mediated neurotoxicity was completely abolished in cultures lacking microglial EP2, indicating that microglial EP2 was critical to LPS-activated microgliamediated neurotoxicity in vitro [10].

Triptolide is the major active component of Tripterygium extracts and possesses potent anti-inflammatory and immunosuppressive properties [11]. Our group demonstrated for the first time that triptolide possesses potent neuroprotective properties both in vitro and in vivo [12]. In an LPS-challenged inflammation model of Parkinson's disease (PD), intraperitoneal injection with triptolide for 24 days significantly improved the behavior of PD rats, decreased DAergic neuron death, and increased DA levels in the striatum [13]. Further study in primary cultured rat microglia indicated that triptolide inhibits LPS-induced microglial activation and suppresses COX-2 expression and PGE2 release [14]. In the current study, we investigated the main pathway of triptolide in LPS-induced inflammatory responses in primary rat microglial cells. We found that triptolide suppressed LPS-induced nitric oxide (NO) production and inducible $\mathrm{NO}$ synthase (iNOS) synthesis in primary rat microglial cells, which in turn protects neuronal cells from microglia-conditioned medium-induced cell injury. Moreover, triptolide inhibits LPS-stimulated NO production in microglia via a signaling mechanism involving EP2 and PKA.

Triptolide was generously provided by Professor PengFeiTu (School of Pharmaceutical Sciences, Peking University, Beijing, China). This white crystalline drug has a melting point of $226^{\circ} \mathrm{C}$ to $240^{\circ} \mathrm{C}$ and, for this study, was $98 \%$ pure, as evaluated by reverse-phase high pressure liquid chromatography. The following materials were used for these studies: LPS (Sigma-Aldrich, St. Louis, MO, USA), a rabbit polyclonal antibody to iNOS (Abcam, Cambridge, UK), a rabbit polyclonal antibody to EP2 (Cayman, MI, USA), a mouse monoclonal antibody to CD11b (Millipore, Billerica, MA, USA), a mouse monoclonal antibody to GAPDH (Sigma-Aldrich), butaprost (Cayman, MI, USA), AH6809 (Cayman, MI, USA), 6Bnz-cAMP (BIOLOG Life Science Institute, Bremen, Germany), 8-pCPT-2-O-Me-cAMP (Millipore, Billerica, MA, USA), KT5720 (Life Technologies, Carlsbad, CA, USA), FBS (Hyclone, Logan, UT, USA), streptomycin and penicillin (Life Technologies), 0.2-ml syringe filters, 96and 24-well tissue culture plates, $100-\mathrm{mm}$ diameter dishes (Corning, NY, USA), Dulbecco's modified Eagle's medium (DMEM), and DMEM/F-12 (Life Technologies).

The immortalized murine BV2 microglial cell line was purchased from Cell Resource Center, Institute of Basic Medical Sciences, Chinese Academy of Medical Sciences (Beijing, China). MN9D cells were kindly provided by
Dr. Bastian Hengerer (Novartis Institute for BioMedical Research, Basel, Switzerland). The two cell lines were maintained in $5 \% \mathrm{CO}_{2}$ at $37^{\circ} \mathrm{C}$ in DMEM/F-12 supplemented with $10 \%$ fetal bovine serum (FBS), $1 \%$ streptomycin, and penicillin. The primary rat microglial cells were prepared as described previously [14]. Briefly, cerebral cortices of 0- to 1-day-old SD rats, devoid of meninges and blood vessels, were dissociated by mild mechanical trituration. The isolated cells were seeded in $75-\mathrm{cm}^{2}$ culture flasks (1.5 brains in a flask) in DMEM/F-12 containing $10 \%$ FBS, 1\% penicillin, and streptomycin. The cultures were maintained at $37^{\circ} \mathrm{C}$ in a humidified atmosphere of $5 \%$ $\mathrm{CO}_{2} / 95 \%$ air. Fourteen days later, the microglia were separated from astrocytes by shaking the flasks at $180 \mathrm{rpm}$ for $2 \mathrm{~h}$. The purity of the enriched microglia was $>95 \%$, as identified by CD11b (dilution, 1:800) immunocytochemical staining. All of the results are expressed as the mean \pm standard deviation (SD) of at least three independent experiments performed in duplicate. One-way analysis of variance (ANOVA) and Newman-Keuls multiple comparison tests were used to compare the groups. The differences were considered to be significant at $P<0.05$. The experimental procedures in this study were approved by the Committee on Animal Care and Usage (Capital Medical University), and efforts were engaged to minimize the number of animal usage and suffering.

To confirm the anti-inflammatory effect of triptolide, we first investigated $\mathrm{NO}$ and iNOS production in the murine BV2 microglial cell line and in primary rat microglial cells. BV2 cells and primary rat microglial cells were cultured in 12-well plates and stimulated with LPS $(0.01 \mu \mathrm{g} / \mathrm{mL})$ for $24 \mathrm{~h}$. At the end of the incubation period, supernatants were collected. NO measurements were made using the Griess Reagent System (Promega, Madison, WI, USA), and iNOS expression was measured by Western blot. In BV2 cells, LPS significantly induced NO release to $8 \mu \mathrm{M}$ compared with $1 \mu \mathrm{M}$ in naïve cells (Figure 1A). In primary microglia cells, LPS significantly induced $\mathrm{NO}$ release to $12 \mu \mathrm{M}$ compared with $2 \mu \mathrm{M}$ in naive cells (Figure 1B). NO is synthesized by a family of NOS consisting of three isoforms: endothelial NOS (eNOS), neuronal NOS (nNOS), and inducible NOS (iNOS) [15]. Among them, NO produced from iNOS [16] promotes the development of neurodegenerative disorders associated with inflammation [17]. In the present study, the increase of $\mathrm{NO}$ correlated well with the induction of iNOS by LPS (Figure 1C, lane 2). BV2 cells and primary rat microglia both showed basal release of nitrite, which has been well demonstrated in previous reports by different laboratories [18-21]. Moreover, Ryuet al. reported that neither iNOS inhibitors nor nonselective nitric-oxide synthase inhibitors had any effect on the basal release of nitrite [22]. 


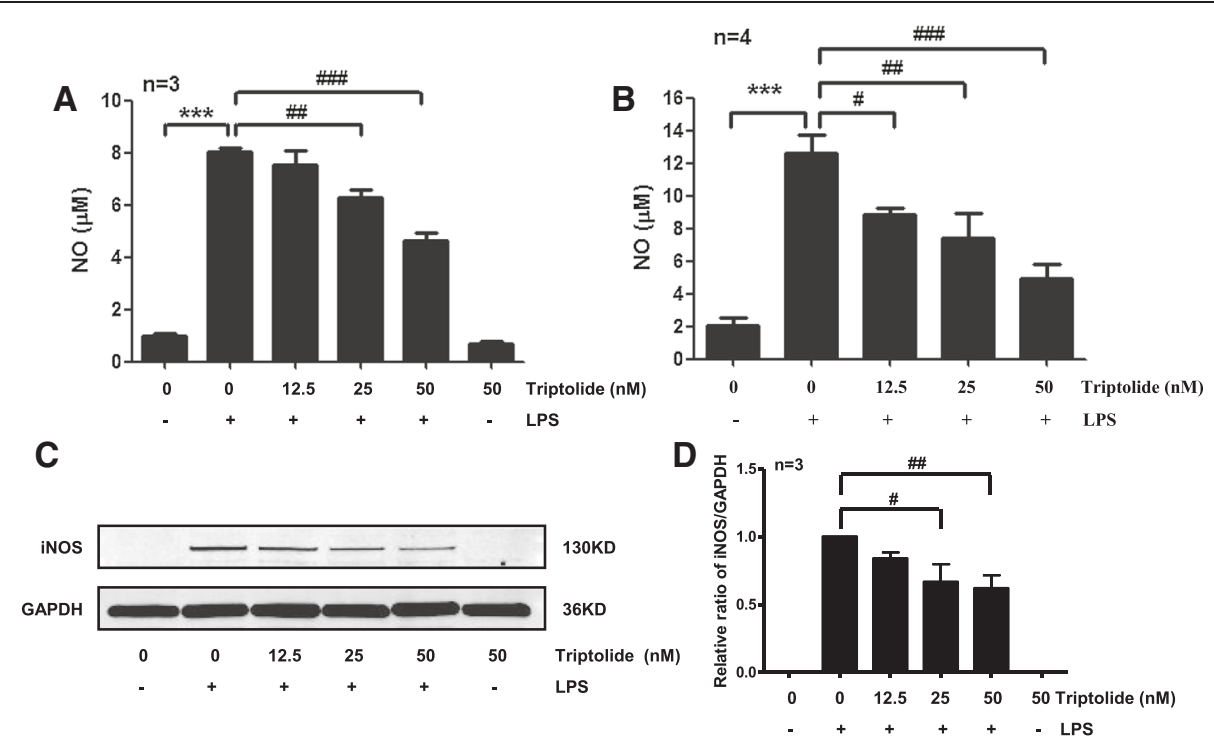

Figure 1 Triptolide suppresses NO production and iNOS expression in LPS-activated microglia. (A) Triptolide reduced NO production in BV2 cells. BV2 cells were stimulated with LPS $(0.01 \mathrm{\mu g} / \mathrm{mL})$ in the presence or absence of different concentrations of triptolide $(0,12.5,25,50 \mathrm{nM})$ for $24 \mathrm{~h}$. At the end of the incubation period, the supernatants were collected for NO measurements. (B) Triptolide reduced NO production in primary rat microglial cells. Primary rat microglial cells were stimulated with LPS $(0.01 \mu \mathrm{g} / \mathrm{mL})$ in the presence or absence of triptolide $(0,12.5,25,50 \mathrm{nM})$ for $24 \mathrm{~h}$. At the end of the incubation period, the supernatants were collected for NO measurements. (C) Triptolide reduced iNOS expression in primary rat microglial cells. Primary rat microglial cells were stimulated with LPS $(0.01 \mu \mathrm{g} / \mathrm{mL})$ in the presence or absence of triptolide $(0,12.5,25,50 \mathrm{nM})$ for $24 \mathrm{~h}$. The cells were then lysed to detect iNOS expression by Western blot. (D) The protein levels were quantified relative to GAPDH levels and normalized to the LPS-stimulated group. ${ }^{* *} P<0.001 .{ }^{\#} P<0.05$, ${ }^{\# \#} P<0.01$, and ${ }^{\# \# \#} P<0.001$.

To investigate the inhibitory effect of triptolide on LPSinduced $\mathrm{NO}$ and iNOS synthesis, primary rat microglial cells were pretreated for $30 \mathrm{~min}$ with different concentrations of triptolide and subsequently stimulated with LPS. As shown in Figure 1A,B, triptolide dose dependently inhibited LPS-induced NO synthesis at concentrations from 12.5 to $50 \mathrm{nM}$. In BV2 cells, pretreatment with triptolide led to a dose-dependent inhibition on LPS-induced NO release by $6 \%(P<0.05)$ at $12.5 \mathrm{nM}, 22 \%(P<0.01)$ at $25 \mathrm{nM}$, and $42 \%(P<0.001)$ at $50 \mathrm{nM}$ (Figure $1 \mathrm{~A})$. In primary microglial cells, pretreatment with triptolide led to a dose-dependent inhibition on LPS-induced NO release by $30 \%(P<0.05)$ at $12.5 \mathrm{nM}, 41 \%(P<0.01)$ at $25 \mathrm{nM}$, and $61 \%(P<0.001)$ at $50 \mathrm{nM}$ (Figure $1 \mathrm{~B})$. As further illustrated in Figure $1 C, D$, the inhibitory effect of triptolide on NO synthesis was due to a dose-dependent inhibition of iNOS synthesis. iNOS synthesis was inhibited at a concentration of $25 \mathrm{nM}$ and decreased significantly at a concentration of $50 \mathrm{nM}$ triptolide. These results were consistent with a previous study in which Shen et al. reported that $30 \mathrm{nM}$ triptolide inhibits NO production in LPS-activated macrophages [23].

Activated microglia are capable of releasing neurotoxic molecules, such as proinflammatory cytokines and toxic oxygen and nitrogen species [24,25]. Accumulating evidence shows that activated microglia can damage or kill neurons in vitro by generating nitric oxide (NO) [26-29].
As microglia secreted increased amount of NO in response to LPS stimulation and triptolide inhibited this effect, we reasoned that triptolide may also reduce the neuronal toxicity of LPS-stimulated microglia-conditioned medium. MN9D cell, a fusion of neuroblastoma with mice embryonic ventral mesencephalic cell, was treated with the conditioned medium for $24 \mathrm{~h}$, and an MTS assay was used to assess cell viability. The medium from microglia treated with only triptolide $(50 \mathrm{nM})$ exhibited no toxicity. However, a $24 \mathrm{~h}$ exposure to medium from LPS-stimulated microglia caused a significant decrease of MN9D cell viability to $85 \%$ of that observed for MN9D cell exposed to medium from untreated microglia. In contrast, there was no significant change of MN9D cell viability between cells exposed to medium from microglia treated with triptolide $(50 \mathrm{nM})$ followed by LPS and unstimulated microglia (Figure 2A). Since triptolide alone did not change the cell viability of MN9D cells or primary rat microglial cells (Figure 2C, $\mathrm{D})$, the results indicated that triptolide-treated microglia attenuated the toxicity of the LPS-stimulated microglia-conditioned medium to MN9D cells.

We confirm the neuroprotective effect of triptolide in SH-SY5Y cells. The neuroblastoma cell line SH-SY5Y is often used in the cellular model of PD due to its dopaminergic ability [30,31]. As shown in Figure 2B, conditioned media from LPS-stimulated primary microglial 
A

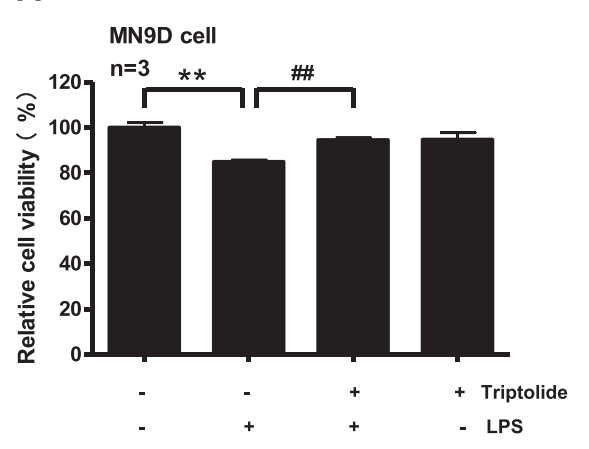

C

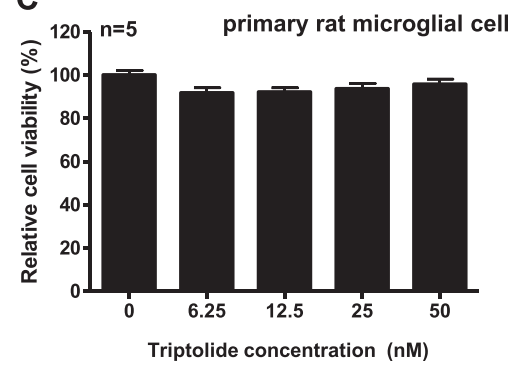

B

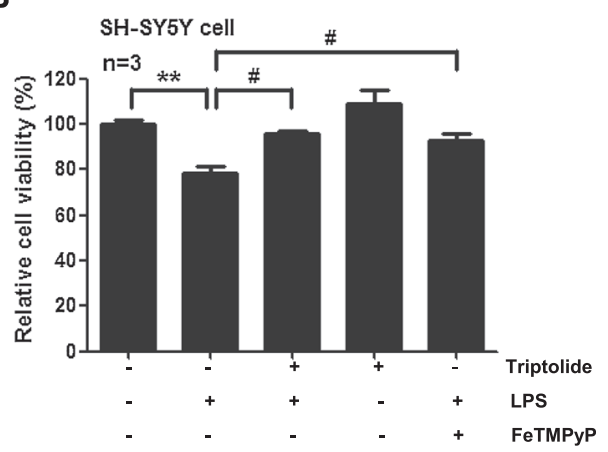

D

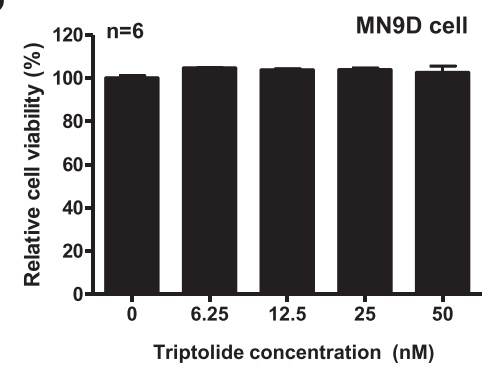

Figure 2 Triptolide protects neuronal cells from the toxicity of LPS-stimulated microglia-conditioned medium. (A) Triptolide attenuated the toxicity of conditioned medium from LPS-stimulated microglia to MN9D cells. MN9D cells treated with conditioned medium from LPS-unstimulated microglia, LPS-stimulated microglia with or without triptolide $(50 \mathrm{nM})$, as well as triptolide alone $(50 \mathrm{nM})$ treated microglia for $24 \mathrm{~h}$. Cell viability was assessed by MTS assay. (B) Triptolide attenuated the toxicity of conditioned medium from LPS-stimulated microglia to SH-SY5Y cells. SH-SY5Y cells treated with conditioned medium from LPS-unstimulated microglia, LPS-stimulated microglia with or without triptolide (50 nM), triptolide alone (50 nM) treated microglia, as well as LPS-stimulated microglia with FeTMPyP $(10 \mu \mathrm{M})$ for $72 \mathrm{~h}$. Cell viability was assessed by MTS assay. (C) Triptolide did not change primary rat microglial cell viability. Primary rat microglial cells were treated with triptolide $(0,6.25,12.5,25,50 \mathrm{nM})$ for $24 \mathrm{~h}$. Cell viability was assessed by MTS assay. (D) Triptolide did not change MN9D cell viability. MN9D cells were treated with triptolide (0, 6.25, 12.5, 25, $50 \mathrm{nM})$ for $24 \mathrm{~h}$. Cell viability was assessed by MTS assay. ${ }^{*} P<0.01 .{ }^{\#} P<0.05$ and ${ }^{\# \#} P<0.01$.

cells significantly $(P<0.01)$ increased cell death of $\mathrm{SH}-$ SY5Y cells. Cell viability decreased to $76 \%$ of cells treated with medium from untreated microglia. This result is consistent with that reported by Liu et al. [32], Munch et al. [33], and Tseng et al. [34]. In contrast, the conditioned media from primary microglia cells pretreated with triptolide prior to LPS stimulation showed little neurotoxicity on SH-SY5Y cells, suggesting that triptolide suppresses microglia-mediated neurotoxicity.

To further investigate the role of NO release from microglia in toxicity of microglia to neuronal cells, we treated microglial cells with peroxynitrite (ONOO-) decomposition catalysts FeTMPyP [5,10,15,20-tetrakis(nmethyl-4'-pyridyl) porphinato iron (III) chloride]. NO reacts with superoxide $\left(\mathrm{O}^{-}\right)$, producing the highly reactive and toxic peroxynitrite (ONOO-) [35]. In the present study, we observed FeTMPyP at $10 \mu \mathrm{M}$ blocked the LPS-induced microglial neurotoxicity in SH-SY5Y cells (Figure 2B), indicating peroxynitrite is a main mediator for the neurotoxicity of LPS-induced microglia.

The above findings that triptolide reduced the amount of proinflammatory factors in microglia and protected neurons from NO stimulation may help establish the pharmacological function of triptolide in neurodegenerative disorders.

Microglial EP2 is critical to the neurotoxicity caused by the activation of cerebral innate immunity. To investigate whether EP2 is involved in the anti-inflammatory effect of triptolide in LPS-stimulated microglia, we first examined EP2 expression in primary rat microglial cells. We observed the basal expression of EP2 in resting microglia (Figure 3A). As a stimulatory G protein coupled receptor (GPCR), EP2 activation stimulates adenylate cyclase (AC). This effect results in an elevation of cytoplasmic cAMP levels, initiating multiple downstream events. To assess the functionality of the EP2 receptor in microglia, the cAMP level was determined by treating microglia with butaprost $(10 \mu \mathrm{M})$, a selective EP2 agonist, or with AH6809 $(10 \mu \mathrm{M})$, an EP2 antagonist. As shown in Figure 3B, there was a trend of increased intracellular cAMP accumulation in microglia treated with $10 \mu \mathrm{M}$ butaprost for $3 \mathrm{~h}$ compared to control. By contrast, the treatment of microglia with $10 \mu \mathrm{M}$ AH6809 for $3 \mathrm{~h}$ decreased the intracellular cAMP accumulation. Butaprost alone increased the basal level of microglia NO production (Figure 3C). This may be due to the iNOS expression influenced by 

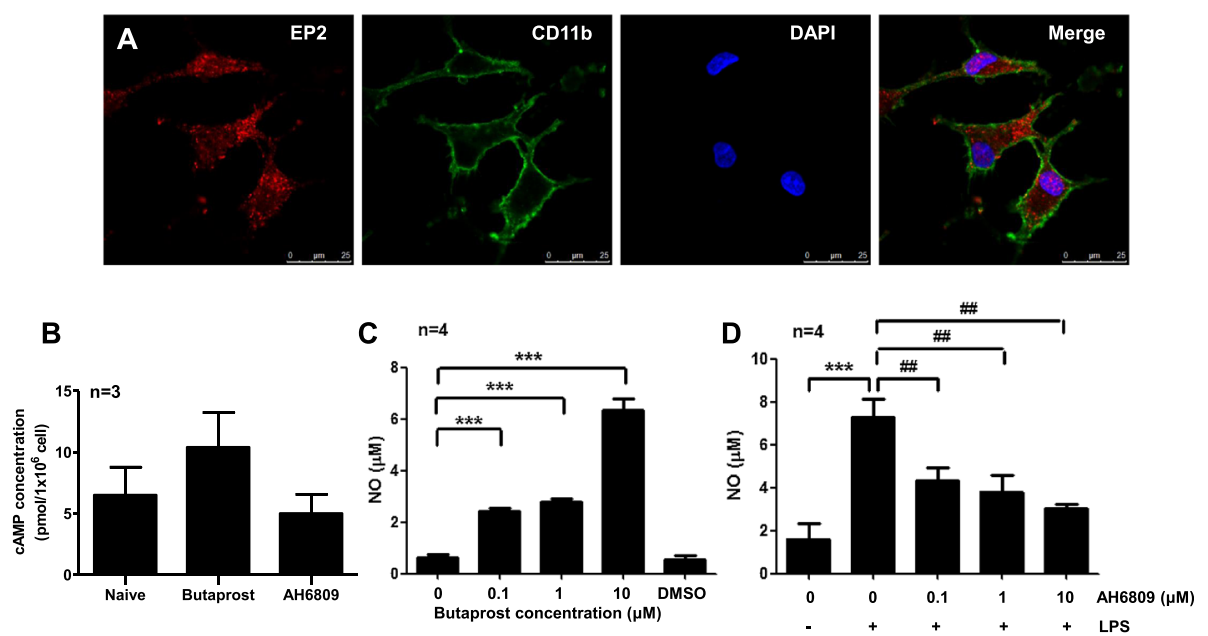

Figure 3 EP2 signaling pathway regulates NO release in primary rat microglial cells. (A) EP2 expression in primary rat microglial cells. Immunofluorescent staining of EP2 and CD11b, as well as the nuclear stain DAPI are shown (scale bar, $25 \mu \mathrm{m}$ ). (B) cAMP accumulation in rat microglia cells left untreated or treated with butaprost $(10 \mu \mathrm{M})$ or AH6809 $(10 \mu \mathrm{M})$ for $3 \mathrm{~h}(n=3)$. (C) Butaprost stimulated NO production in resting microglia. Primary rat microglial cells were stimulated with different concentrations of butaprost $(0,0.1,1,10 \mu \mathrm{M})$ for $24 \mathrm{~h}$. At the end of the incubation period, the supernatants were collected for NO measurements. (D) AH6809 suppressed NO production in LPS-activated microglia. Primary rat microglial cells were unstimulated or stimulated with LPS $(0.01 \mu \mathrm{g} / \mathrm{mL})$ in the presence or absence of AH6809 $(0.1,1,10 \mu \mathrm{M})$ for $24 \mathrm{~h}$. At the end of the incubation period, the supernatants were collected for NO measurements. ${ }^{* *} P<0.001$ and ${ }^{\# \#} P<0.01$.

butaprost; as Quanet al. reported, iNOS mRNA level in resting rat microglia was increased more than tenfold after $200 \mathrm{nM}$ and $2 \mu \mathrm{M}$ butaprost treatment [36]. Another EP2 agonist, ONO-AE1-259 was also reported to increase iNOS mRNA level in ileal tissue [37]. By contrast, AH6809 inhibited LPS-induced NO synthesis (Figure 3D). Since NO levels in the medium are also affected by proliferation and death of the treated microglia, we observed the cell viability after EP2 agonist and antagonist and the PKA agonist and antagonist treatment in BV2 cells and found no changes (Additional file 1: Figure S1). Thus, under an innate inflammatory stimulus, microglia EP2 signaling potentiated a classically activated proinflammatory response, inducing $\mathrm{NO}$ production.

To evaluate the involvement of the EP2 pathway in triptolide's effect, real-time PCR of EP2 was performed on a Stratagene Mx3000P (Agilent, Santa Clara, CA, USA) using the following parameters: $95^{\circ} \mathrm{C}$ for $10 \mathrm{~min}$, followed by 40 cycles at $95^{\circ} \mathrm{C}$ for $15 \mathrm{~s}, 60^{\circ} \mathrm{C}$ for $1 \mathrm{~min}$, and $72^{\circ} \mathrm{C}$ for $1 \mathrm{~min}$ using the specific primer sets. The following primer pairs were employed: $5^{\prime}$ - TTGCTCTTCTGTTCTCTG CCG - 3' (upper, 538 to 558) and 5' - CAGCTGAAGGTA TGCGGTCC - 3' (lower, 642 to 623) for the amplification of rat EP2 receptor (GenBank accession No. NM_031088) and 5' - ATCGCTGACAGGATGCAGAAG - 3' (upper, 925 to 945$)$ and $5^{\prime}$ - AGAGCCACCAATCCACACAGA $3^{\prime}$ (lower, 1,032 to 1,012) for the amplification of rat $\beta$ actin. Firstly, we observed the EP2 mRNA level at 1, 3, 6, 12 , and $24 \mathrm{~h}$ after LPS induction and found that LPS augmented the EP2 expression significantly at $6 \mathrm{~h}$ (Figure 4A).
The relative expression level compared with that of resting microglia increased to nearly 12 -fold with LPS, which is similar as that reported by Noda et al. [38]. Moreover, we observed a prompt downregulation of EP2 mRNA level after 12-h LPS treatment. Johansson et al. reported that stimulation of macrophages with LPS $(10 \mathrm{ng} / \mathrm{ml})$ induced a rapid increase in EP2 mRNA within $1 \mathrm{~h}$ followed by a prompt downregulation by $6 \mathrm{~h}$ [39]. The different time of EP2 mRNA upregulation between macrophages and microglia maybe caused by their local microenvironment, as well as the differences between periphery and central inflammation, but the similar changes of EP2 expression induced by LPS indicate that EP2 expression is tightly regulated by inflammatory stimuli.

To investigate the effect of triptolide on LPS-regulated EP2 expression, microglia were pretreated for $30 \mathrm{~min}$ with triptolide $(50 \mathrm{nM})$ and subsequently stimulated with LPS. As shown in Figure 4B, $50 \mathrm{nM}$ triptolide almost completely inhibited LPS-induced EP2 expression. To confirm the triptolide inhibition of EP2 expression, we next monitored the protein level changes of EP2 by Western blot (Figure 4C,D). Although the changes in EP2 protein levels were not as dramatic as were observed for mRNA levels, triptolide did inhibit EP2 protein expression.

To confirm the necessary role of EP2, we treated primary rat microglial cells with butaprost/AH6809 and triptolide before LPS stimulation. As shown in Figure 5A, treatment with triptolide or AH6809 $(10 \mu \mathrm{M})$ alone both decreased NO production in LPS-treated microglia to 
A

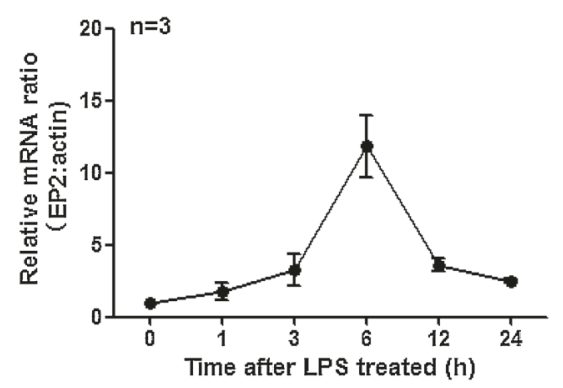

C

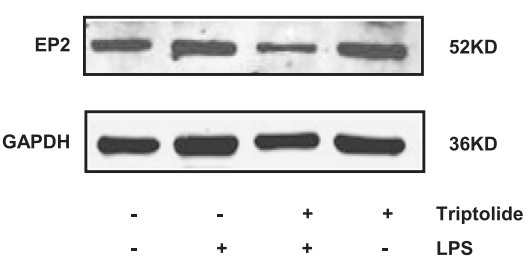

B

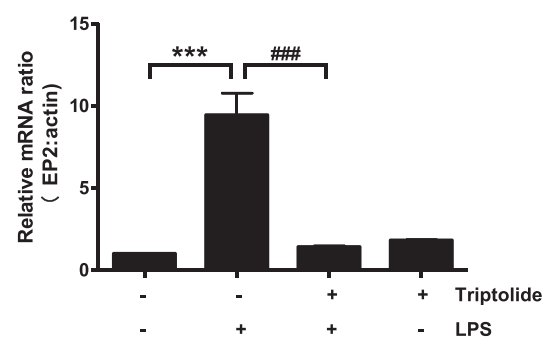

D

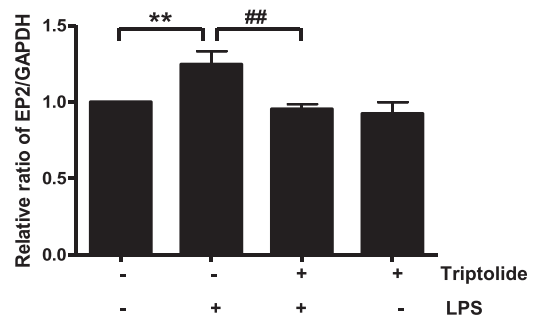

Figure 4 Triptolide regulates EP2 expression in LPS-stimulated microglia. (A) Rat primary microglia cells were stimulated with LPS (0.01 $\mu \mathrm{g} / \mathrm{mL})$ for $0,1,3,6,12$, and $24 \mathrm{~h}$. The cells were lysed for EP2 expression by real-time PCR analysis. (B) Rat primary microglia cells were stimulated with LPS $(0.01 \mathrm{\mu g} / \mathrm{mL})$ in the presence or absence of triptolide $(50 \mathrm{nM})$ for $6 \mathrm{~h}$. The cells were lysed for EP2 expression by real-time PCR analysis. (C) Primary rat microglial cells were stimulated with LPS $(0.01 \mu \mathrm{g} / \mathrm{mL})$ in the presence or absence of triptolide $(50 \mathrm{nM})$ for $24 \mathrm{~h}$. The cells were lysed for EP2 expression by Western blot. (D) The protein levels were quantified relative to GAPDH levels and normalized to the naiive group (untreated cells). ${ }^{* *} P<0.01$. ${ }^{* * *} P<0.001$. ${ }^{\# \#} P<0.01$ and ${ }^{\# \# \#} P<0.001$.

similar levels as were observed in normal microglia. Moreover, the combination of triptolide and AH6809 failed to further decrease NO production. Conversely, the addition of butaprost $(0.1 \mu \mathrm{M})$ partially reversed the triptolide-induced inhibition of $\mathrm{NO}$ production (Figure 5A). Taken together, these results demonstrate that triptolide inhibits LPS-stimulated NO production in microglia via a signaling mechanism involving EP2. These results also indicate that triptolide regulation of the EP2 pathway is a potential therapeutic mechanism for the treatment of inflammation-related neurological disorders.

EP2 activation leads to increased levels of cytoplasmic cAMP, which then initiates multiple downstream events via the PKA or Epac pathways. To differentiate between these two pathways, we added the PKA-specific activator 6-BnzcAMP (6Bnz) or the Epac-specific activator 8-pCPT-2-OMe-cAMP (8-CPT) to triptolide-treated microglia. We found that $6 \mathrm{Bnz}(10 \mu \mathrm{M})$ but not 8 -CPT $(10 \mu \mathrm{M})$ increased NO production in triptolide-LPS treated microglia (Figure 5B), indicating that EP2-PKA was mainly involved in the triptolide inhibition. This specificity was most likely due to the nature of LPS stimulation. Peters-Golden et al. reported that in rat alveolar macrophages, the downmodulation of LPS-induced TNF- $\alpha$ by $\mathrm{PGE}_{2}$ is dependent on cAMP-PKA activation. This was concluded given that the selective PKA activating cAMP analog $6 \mathrm{Bnz}$ but not the Epac- 1 activating analog 8 -CPT inhibited TNF- $\alpha$ production [40]. Their recent work also indicates that EP2PKA, rather than Epac-1, is involved in the enhancement of LPS-induced NO [41]. This result suggests that the EP2PKA pathway is very important for the anti-inflammatory effect of triptolide in microglia. More studies are needed to clarify whether the EP2-PKA signaling pathway is the dominant mediator of harmful EP2-mediated effects in microglia.

We further observe this effect in BV2 cells, and found 6Bnz $(10 \mu \mathrm{M})$ increased NO production in triptolideLPS treated microglia (Figure $5 \mathrm{C}$ ). To confirm that PKA is indeed responsible for the inhibition of $\mathrm{NO}$ generation by triptolide, BV2 cells were pre-treated with the PKA inhibitor KT5720, and the PKA-specific activator 6Bnz was added before triptolide treatment. We found that 6Bnz $(10 \mu \mathrm{M})$ increased NO production in triptolideLPS treated microglia, KT5720 attenuated NO production to an extent similar to that observed with triptolide treatment (Figure $5 \mathrm{C}$ ), suggesting that PKA is responsible for the triptolide inhibition.

The direct target of triptolide in the regulation of EP2PKA pathway remains unknown. Liu et al. report that triptolide directly binds to human XPB, a subunit of the transcription factor TFIIH, leading to the inhibition of RNA polymerase II-mediated transcription in tumor cells [42]. However, these authors used higher concentrations 

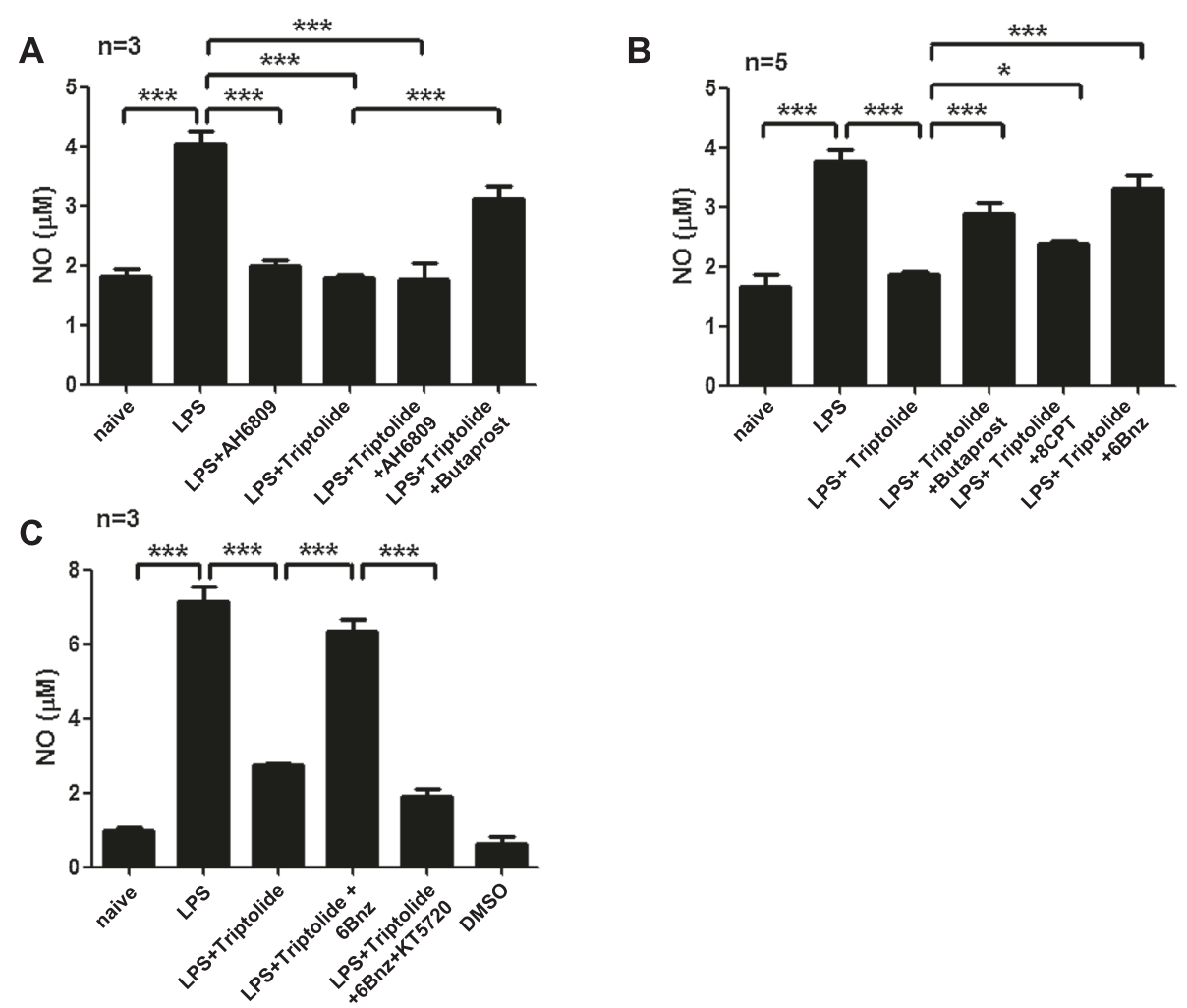

Figure 5 EP2-PKA pathway is important in LPS-stimulated NO production and triptolide inhibition. (A) Primary rat microglial cells were treated with LPS $(0.01 \mu \mathrm{g} / \mathrm{mL})$, LPS plus AH6809 $(10 \mu \mathrm{M})$, LPS plus triptolide $(50 \mathrm{nM})$, LPS plus triptolide plus AH6809, and LPS plus triptolide plus butaprost $(0.1 \mu \mathrm{M})$ for $24 \mathrm{~h}$. At the end of the incubation period, the supernatants were collected for NO measurements. (B) Primary rat microglial cells were treated with LPS $(0.01 \mu \mathrm{g} / \mathrm{mL})$, LPS plus triptolide $(50 \mathrm{nM})$, LPS plus triptolide plus butaprost $(0.1 \mu \mathrm{M})$, LPS plus triptolide plus 8-CPT (10 $\mu$ M), or LPS plus triptolide plus $6 \mathrm{Bnz}(10 \mu \mathrm{M})$ for $24 \mathrm{~h}$. At the end of the incubation period, the supernatants were collected for NO measurements. (C) BV2 cells were treated with LPS $(0.01 \mu \mathrm{g} / \mathrm{mL})$, LPS plus triptolide $(50 \mathrm{nM})$, LPS plus triptolide plus $6 \mathrm{Bnz}(10 \mu \mathrm{M})$, and LPS plus triptolide plus $6 \mathrm{Bnz}(10 \mu \mathrm{M})$ plus KT5720 (1 $\mu \mathrm{M})$ for $24 \mathrm{~h}$. At the end of the incubation period, the supernatants were collected for NO measurements. ${ }^{*} P<0.05$ and ${ }^{* * *} P<0.001$.

of triptolide ( 1 to $100 \mu \mathrm{M})$ to inhibit tumor cell proliferation. We used lower concentrations of triptolide (no more than $50 \mathrm{nM}$ ) to suppress inflammation and to protect neurons in the brain. Therefore, different targets may exist for triptolide with respect to the modulation of the inflammatory response in the CNS. Recently, Shen et al. reported that triptolide inhibited TAK1 kinase activity by interfering with the formation of the TAK1-TAB1 complex, and that the binding affinity of triptolide to TAB1 was highly correlated with the inhibitory activity of triptolide against the MAPK pathway activation in macrophages [23]. Although macrophages and microglia are both tissue-resident immune cells during inflammation and the effective triptolide concentration was similar in both cell types, it remains to be investigated whether TAB1 is the target of triptolide in microglia.

\section{Conclusions}

The present study demonstrates that triptolide inhibits LPS-stimulated NO production in microglia via a signaling mechanism involving EP2 and PKA. The finding that triptolide reduces the proinflammatory factors in microglia and protects neurons from inflammatory stimulation may help establish the pharmacological function of triptolide in neurodegenerative disorders. Moreover, the observation of inflammatory EP2 signaling in primary microglia also provides important evidence with respect to EP2 in the regulation of innate immunity in the CNS.

\section{Additional file}

Additional file 1: Figure S1. Microglia proliferations did not change after pharmacological treatments. BV2 cells treated with butaprost $(0.1 \mu \mathrm{M})$, AH6809 $(10 \mu \mathrm{M}), 8$-CPT $(10 \mu \mathrm{M}), 6 \mathrm{Bnz}(10 \mu \mathrm{M}), \mathrm{KT} 5720(1 \mu \mathrm{M})$, and DMSO $(0.1 \%)$ for $24 \mathrm{~h}$. Cell viability was assessed by MTS assay.

\section{Abbreviations}

LPS: lipopolysaccharide; NO: nitric oxide; iNOS: inducible NO synthase; COX2: cyclooxygenase-2; $P_{G E}$ : prostaglandin $E_{2}$; CNS: central nervous system; PD: Parkinson's disease; GPCR: G protein coupled receptor; AC: adenylate cyclase; PKA: protein kinase A; Epac: exchange proteins that are directly activated by CAMP; 6Bnz: 6-Bnz-cAMP; 8-CPT: 8-pCPT-2-O-Me-CAMP; MAPK: mitogen-activated protein kinase; DMEM: Dulbecco's modified Eagle's medium; FBS: fetal bovine serum; GAPDH: glyceraldehyde-3-phosphate dehydrogenase; PBS: phosphate-buffered saline; PCR: polymerase chain reaction; SD: standard deviation. 


\section{Competing interests}

The authors declare that they have no competing interests.

\section{Authors' contributions}

TZ designed the study, performed the experiments, and wrote the manuscript. XMW supervised the design of the study, analyzed the data, and wrote the manuscript. XLG and GZH performed the experiments. All authors read and approved the final manuscript.

\section{Acknowledgements}

This study was supported by the Chinese National Basic Research Program (2011CB504100), the National Natural Science Foundation of China (81030062), the Projects of Beijing Municipality (TJSHG201310025006), and the Beijing Higher Education Young Elite Teacher Project (YETP1667).

\section{Author details}

${ }^{1}$ Department of Neurobiology, Capital Medical University, Beijing Institute for Brain Disorders and Key Laboratory for Neurodegenerative Disorder, Ministry of Education, No. 10 Xitoutiao, Youanmenwai, Fengtai District, Beijing 100069, China. ${ }^{2}$ Department of Physiology, Capital Medical University, No. 10 Xitoutiao, Youanmenwai, Fengtai District, Beijing 100069, China.

Received: 29 September 2014 Accepted: 2 March 2015

Published online: 14 March 2015

\section{References}

1. Liu B, Hong JS. Role of microglia in inflammation-mediated neurodegenerative diseases: mechanisms and strategies for therapeutic intervention. J Pharmacol Exp Ther. 2003;304(1):1-7.

2. Amor S, Peferoen LA, Vogel DY, Breur M, van der Valk P, Baker D, et al. Inflammation in neurodegenerative diseases - an update. Immunology. 2013;142(2):151-66.

3. Calabrese V, Mancuso C, Calvani M, Rizzarelli E, Butterfield DA, Stella AM. Nitric oxide in the central nervous system: neuroprotection versus neurotoxicity. Nat Rev Neurosci. 2007:8(10):766-75.

4. Kim YS, Joh TH. Microglia, major player in the brain inflammation: their roles in the pathogenesis of Parkinson's disease. Exp Mol Med. 2006;38(4):333-47.

5. Tambuyzer BR, Ponsaerts P, Nouwen EJ. Microglia: gatekeepers of central nervous system immunology. J Leukoc Biol. 2009;85(3):352-70.

6. ladecola C, Niwa K, Nogawa S, Zhao X, Nagayama M, Araki E, et al. Reduced susceptibility to ischemic brain injury and N-methyl-D-aspartate-mediated neurotoxicity in cyclooxygenase-2-deficient mice. Proc Natl Acad Sci USA. 2001;98(3):1294-9.

7. Serrano GE, Lelutiu N, Rojas A, Cochi S, Shaw R, Makinson CD, et al. Ablation of cyclooxygenase-2 in forebrain neurons is neuroprotective and dampens brain inflammation after status epilepticus. J Neurosci. 2011;31(42):14850-60.

8. Grosser T, Yu Y, Fitzgerald GA. Emotion recollected in tranquility: lessons learned from the COX-2 saga. Annu Rev Med. 2010;61:17-33.

9. Jiang J, Dingledine R. Prostaglandin receptor EP2 in the crosshairs of anti-inflammation, anti-cancer, and neuroprotection. Trends Pharmacol Sci. 2013;34(7):413-23.

10. Shie FS, Montine KS, Breyer RM, Montine TJ. Microglial EP2 is critical to neurotoxicity from activated cerebral innate immunity. Glia. 2005;52(1):70-7.

11. Lu L, Li F, Wang X. Novel anti-inflammatory and neuroprotective agents for Parkinson's disease. CNS Neurol Disord Drug Targets. 2010;9(2):232-40.

12. Wang X, Liang XB, Li FQ, Zhou HF, Liu XY, Wang JJ, et al. Therapeutic strategies for Parkinson's disease: the ancient meets the future-traditional Chinese herbal medicine, electroacupuncture, gene therapy and stem cells. Neurochem Res. 2008;33(10):1956-63.

13. Zhou HF, Liu XY, Niu DB, Li FQ, He QH, Wang XM. Triptolide protects dopaminergic neurons from inflammation-mediated damage induced by lipopolysaccharide intranigral injection. Neurobiol Dis. 2005;18(3):441-9.

14. Gong $Y$, Xue B, Jiao J, Jing L, Wang X. Triptolide inhibits COX-2 expression and PGE2 release by suppressing the activity of NF-kappaB and JNK in LPS-treated microglia. J Neurochem. 2008;107(3):779-88.

15. Andrew PJ, Mayer B. Enzymatic function of nitric oxide synthases. Cardiovasc Res. 1999;43(3):521-31.

16. Griffith OW, Stuehr DJ. Nitric oxide synthases: properties and catalytic mechanism. Annu Rev Physiol. 1995;57:707-36.
17. Singh S, Das T, Ravindran A, Chaturvedi RK, Shukla Y, Agarwal AK, et al. Involvement of nitric oxide in neurodegeneration: a study on the experimental models of Parkinson's disease. Redox Rep. 2005;10(2):103-9.

18. Fiebich BL, Lieb K, Engels S, Heinrich M. Inhibition of LPS-induced p42/44 MAP kinase activation and iNOS/NO synthesis by parthenolide in rat primary microglial cells. J Neuroimmunol. 2002;132(1-2):18-24.

19. Lau FC, Bielinski DF, Joseph JA. Inhibitory effects of blueberry extract on the production of inflammatory mediators in lipopolysaccharide-activated BV2 microglia. J Neurosci Res. 2007;85(5):1010-7. doi:10.1002/jnr.21205.

20. Lieb K, Engels S, Fiebich BL. Inhibition of LPS-induced iNOS and NO synthesis in primary rat microglial cells. Neurochem Int. 2003;42(2):131-7.

21. Pangestuti R, Bak SS, Kim SK. Attenuation of pro-inflammatory mediators in LPS-stimulated BV2 microglia by chitooligosaccharides via the MAPK signaling pathway. Int J Biol Macromol. 2011;49(4):599-606. doi:10.1016/j. ijbiomac.2011.06.014.

22. Ryu J, Pyo H, Jou I, Joe E. Thrombin induces $N O$ release from cultured rat microglia via protein kinase C, mitogen-activated protein kinase, and NFkappa B. J Biol Chem. 2000;275(39):29955-9. doi:10.1074/jbc.M001220200.

23. Lu Y, Zhang $Y$, Li L, Feng $X$, Ding $S$, Zheng W, et al. TAB1: a target of triptolide in macrophages. Chem Biol. 2014;21(2):246-56.

24. Colton CA, Gilbert DL. Production of superoxide anions by a CNS macrophage, the microglia. FEBS letters. 1987;223(2):284-8.

25. Klegeris A, McGeer PL. Rat brain microglia and peritoneal macrophages show similar responses to respiratory burst stimulants. J Neuroimmunol. 1994;53(1):83-90.

26. Boje KM, Arora PK. Microglial-produced nitric oxide and reactive nitrogen oxides mediate neuronal cell death. Brain Res. 1992;587(2):250-6.

27. Chao CC, Hu S, Molitor TW, Shaskan EG, Peterson PK. Activated microglia mediate neuronal cell injury via a nitric oxide mechanism. J Immunol. 1992;149(8):2736-41.

28. Goodwin JL, Uemura E, Cunnick JE. Microglial release of nitric oxide by the synergistic action of beta-amyloid and IFN-gamma. Brain Res. 1995;692(1-2):207-14

29. Meda L, Cassatella MA, Szendrei Gl, Otvos Jr L, Baron P, Villalba M, et al. Activation of microglial cells by beta-amyloid protein and interferongamma. Nature. 1995;374(6523):647-50. doi:10.1038/374647a0.

30. Biedler JL, Roffler-Tarlov S, Schachner M, Freedman LS. Multiple neurotransmitter synthesis by human neuroblastoma cell lines and clones. Canc Res. 1978;38(11 Pt 1):3751-7.

31. Farooqui SM. Induction of adenylate cyclase sensitive dopamine D2receptors in retinoic acid induced differentiated human neuroblastoma SHSY-5Y cells. Life Sci. 1994;55(24):1887-93.

32. Liu RP, Zou M, Wang JY, Zhu JJ, Lai JM, Zhou LL, et al. Paroxetine ameliorates lipopolysaccharide-induced microglia activation via differential regulation of MAPK signaling. J Neuroinflammation. 2014;11:47. doi:10.1186/1742-2094-11-47.

33. Munch G, Gasic-Milenkovic J, Dukic-Stefanovic S, Kuhla B, Heinrich K, Riederer $P$, et al. Microglial activation induces cell death, inhibits neurite outgrowth and causes neurite retraction of differentiated neuroblastoma cells. Exp Brain Res. 2003;150(1):1-8. doi:10.1007/s00221-003-1389-5.

34. Tseng YT, Hsu YY, Shih YT, Lo YC. Paeonol attenuates microglia-mediated inflammation and oxidative stress-induced neurotoxicity in rat primary microglia and cortical neurons. Shock. 2012;37(3):312-8. doi:10.1097/SHK.0b013e31823fe939.

35. Ischiropoulos H, Zhu L, Beckman JS. Peroxynitrite formation from macrophagederived nitric oxide. Arch Biochem Biophys. 1992;298(2):446-51.

36. Quan Y, Jiang J, Dingledine R. EP2 receptor signaling pathways regulate classical activation of microglia. J Biol Chem. 2013;288(13):9293-302.

37. Tajima T, Murata T, Aritake K, Urade Y, Michishita M, Matsuoka T, et al. EP2 and EP4 receptors on muscularis resident macrophages mediate LPSinduced intestinal dysmotility via iNOSupregulation through CAMP/ERK signals. Am J Physiol Gastrointest Liver Physiol. 2012;302(5):G524-34. doi:10.1152/ajpgi.00264.2011.

38. Noda M, Kariura Y, Pannasch U, Nishikawa K, Wang L, Seike T, et al. Neuroprotective role of bradykinin because of the attenuation of pro-inflammatory cytokine release from activated microglia. J Neurochem. 2007;101(2):397-410.

39. Johansson JU, Pradhan S, Lokteva LA, Woodling NS, Ko N, Brown HD, et al. Suppression of inflammation with conditional deletion of the prostaglandin E2 EP2 receptor in macrophages and brain microglia. J Neurosci. 2013;33(40):16016-32. doi:10.1523/JNEUROSCI. 2203-13.2013. 
40. Aronoff DM, Carstens JK, Chen GH, Toews GB, Peters-Golden M. Short communication: differences between macrophages and dendritic cells in the cyclic AMP-dependent regulation of lipopolysaccharide-induced cytokine and chemokine synthesis. J Interferon Cytokine Res. 2006;26(11):827-33.

41. Kim SH, Serezani CH, Okunishi K, Zaslona Z, Aronoff DM, Peters-Golden M. Distinct protein kinase $A$ anchoring proteins direct prostaglandin E2 modulation of toll-like receptor signaling in alveolar macrophages. J Biol Chem. 2011;286(11):8875-83.

42. Titov DV, Gilman B, He QL, Bhat S, Low WK, Dang Y, et al. XPB, a subunit of $\mathrm{TFIIH}$, is a target of the natural product triptolide. Nat Chem Biol. 2011;7(3):182-8.

\section{Submit your next manuscript to BioMed Central and take full advantage of:}

- Convenient online submission

- Thorough peer review

- No space constraints or color figure charges

- Immediate publication on acceptance

- Inclusion in PubMed, CAS, Scopus and Google Scholar

- Research which is freely available for redistribution 